\title{
O JULGAMENTO DA ADI 4.277: ANÁLISE DOS VOTOS DOS MINISTROS DO STF A LUZ DA TEORIA DO RECONHECIMENTO DE NANCY FRASER E AXEL HONNETH
}

Jessica Cristianetti ${ }^{1}$

\section{Resumo}

O objetivo geral consiste em estudar o debate entre o embasamento teórico de Fraser e de Honneth, com seus reflexos no julgamento da ADI 4277-DF pelo STF, criticando discursos implícitos insuscetíveis de desestabilizar as identidades sexuais binárias. Como objetivos específicos intenta-se confrontar criticamente os referenciais teóricos dos referidos filósofos; revelar e criticar a estratégia argumentativa pressuposta aos votos dos Ministros do STF no julgamento da ADI 4277-DF, compreender qual das teorias filosóficas possui maior alcance teórico para interpretar e criticar os votos. A título de considerações finais é possível entender que Fraser explana recursos conceituais que revelam maior alcance teórico para interpretar e para criticar o voto do Ministro-Relator e dos Ministros Gilmar Mendes e Ricardo Lewandowski, propugnando uma teoria feminista que se contrapõe à essencialização identitária e ao binarismo de gênero - mas sem anular a autonomia do sujeito - assumindo como objetivos a descrição das desigualdades e a formulação de um projeto emancipatório, por meio de contrapúblicos subalternos. Para tanto, a pesquisa se estrutura pelo método fenomenológico-hermenêutico. $\mathrm{O}$ método de indução analítica (método de abordagem) também será utilizado. A técnica de pesquisa envolverá a documentação indireta e será empregada a pesquisa documental.

Palavras-chave: Binarismo Sexual. Direitos fundamentais. Minorias. Teoria do Reconhecimento. União entre casais do mesmo sexo.

\footnotetext{
${ }^{1}$ Doutoranda em Direito Público pela Universidade do Vale dos Sinos - UNISINOS na linha de pesquisa: Hermenêutica, Constituição e Concretização de Direitos, Bolsista CNPq. E-mail: jessicacristianetti@hotmail.com
} 


\section{INTRODUÇÃO}

Primeiramente, enseja-se investigar os aportes teóricos das teorias de Honneth e de Fraser, para que se possa compreender como, partindo de perspectivas diversas, desenvolvem o tema do reconhecimento e quais os reflexos filosóficos de suas teorias na análise da temática da concretização dos direitos fundamentais de minorias gays e lésbicas no STF, especificamente no tocante à ADI 4277-DF. Para tanto, intenta-se analisar a perspectiva tridimensional de Fraser (2010), sua concepção de esfera pública pós-Westfaliana e o paradigma da autorrealização delineado por Honneth (2003a), assim como sua concepção de liberdade social, com o fito de compreender qual dessas teorias indica maior alcance para efetivar direitos de grupos LGBT.

A relevância do presente trabalho se justifica, pois há ineditismo na abordagem que conecta filosofia do reconhecimento e Teoria da Constituição, de forma que a conexão entre investigação jurídica e filosófica contribui para consolidar os pilares da Filosofia Constitucional - ramo fundamental de estudo da ciência do direito. $\mathrm{O}$ debate entre os autores é essencial para fundamentar filosoficamente os posicionamentos dos Ministros do STF na efetivação dos direitos de casais homossexuais consubstanciada no julgamento da ADI 4277-DF, revelando discursos implícitos na estratégia argumentativa dos votos que ainda consagram o binarismo sexual.

O problema de pesquisa do presente estudo questiona: em que medida os aportes teóricos dos referidos filósofos podem elucidar - ou criticar - a estratégia argumentativa implícita aos votos dos Ministros do STF no julgamento da $\mathrm{ADI}$ 4277-DF e quais das respectivas estruturas conceituais revelam maior alcance para desconstruir o binarismo sexual?

Com efeito, o objetivo geral desta pesquisa consiste em estudar o debate entre o embasamento teórico de Fraser e de Honneth, com seus reflexos no julgamento da ADI 4277-DF pelo plenário do STF, criticando discursos implícitos insuscetíveis de desestabilizar as identidades sexuais binárias.

Objetivos específicos: confrontar criticamente os referenciais teóricos de Fraser e de Honneth, com ênfase na dimensão deontológica do reconhecimento; revelar e de criticar a estratégia argumentativa pressuposta aos votos do Ministro-Relator Carlos Ayres de Brito, Ricardo Lewandowski, Gilmar Mendes, Cesar Peluso, Carmem Lucia, Celso Mello e Ellen Gracie no julgamento da ADI 4277-DF, especificamente no que toca à temática do binarismo sexual. Avaliar-se-á também em que medida os votos dos Ministros Ellen Gracie, Marco Aurelio e Celso Mello atendem - ou não - à perspectiva deontológica. Investigar-se-á ainda a possível aproximação conceitual entre a ideia de Constitucionalismo Fraternal e o sentido de solidariedade cívica, que é pressuposto para a ideia de liberdade social, concebida por Honneth.

Para tanto, a pesquisa se estrutura pelo método fenomenológico-hermenêutico, por se tratar de um instrumento de abordagem que pretende aproximar o sujeito e o objeto a ser pesquisado. O método de indução 
analítica (método de abordagem) também será utilizado. Assim, seguindo a indução analítica, a pesquisa trabalha de baixo para cima, iniciando-se pela análise contínua e aprofundada do conteúdo dos votos dos Ministros, para estabelecer conceitos e proposições teóricas que se articularão ao caso estudado. As construções explicativas são desenvolvidas pela articulação entre o quadro de referência e o conteúdo dos votos. A técnica de pesquisa envolverá a documentação indireta, por meio da pesquisa bibliográfica do referencial teórico de Fraser e de Honneth. Outrossim, também será empregada a pesquisa documental (documentação indireta), por meio da coleta de dados atinentes à investigação jurisprudencial do conteúdo da argumentação desenvolvida pelos Ministros no julgamento da ADI 4277-DF.

\section{TEORIA DO RECONHECIMENTO}

Primeiramente, buscar-se-á analisar o debate acerca dos princípios que norteiam a Teoria do Reconhecimento entre a filósofa norte-americana Nancy Fraser e o filósofo alemão Axel Honneth, primeiramente tencionando expor suas perspectivas para, ao final do trabalho, reconhecer qual delas se evidencia como mais adequada à discussão aqui pretendida.

Para início de discussão, importa ressaltar que ambos os doutrinadores concentram-se fundamentalmente em "[...] reconstruir os fundamentos conceituais da teoria crítica e, com a esperança de satisfazer seus imperativos, se tem idealizado um marco no qual a categoria de reconhecimento desempenha um papel importante." (HONNETH; FRASER, 2003b, p. 150). Nesse contexto, Honneth e Fraser delineiam suas teorias do reconhecimento sob duas perspectivas diferentes, com o objetivo de alcançar propostas próprias de renovação da Teoria Crítica, como se analisará adiante.

Inicialmente, Fraser (2003b) foca sua proposta nos discursos descentrados de crítica social, articulando sua crítica com o contexto social e centrando-se nos paradigmas populares da justiça social que, em sua concepção, criam as gramáticas hegemônicas de discussão e de deliberação. Trata-se de formas discursivas despersonalizadas, com o propósito de desconectar a teoria da filosofia polarizada no sofrimento do indivíduo. Nesse ponto de vista, tais paradigmas populares de justiça conglobam a redistribuição e o reconhecimento.

Fraser leciona que a teoria crítica é policêntrica e multilateral, e contrapõe-se à teoria de Honneth (2003b; 2003c) - cuja base é a psicologia moral - o que é objeto de crítica pela estudiosa. (Fraser, 2003b, p. 157). Portanto, em consonância com Fraser (2003), a injustiça redistributiva surge quando os bens econômicos são divididos de forma a prejudicar determinadas pessoas, refletindo-se, por exemplo, quando homens recebem salários maiores do que mulheres, ou quando gays são privados do direito à herança de seus parceiros, no caso de uniões entre homossexuais. Nessa seara, segundo a teórica feminista, “[...] o resultado é uma estrutura econômica 
que gera formas específicas de injustiça distributiva de gênero, incluindo a exploração de gênero, a marginalização econômica e a privação". (FRASER, 2003, p. 20). Ademais, a má distribuição configura um problema relativo às classes sociais, e o não reconhecimento, a seu turno, é compreendido como forma de injustiça decorrente da subordinação de status, que estabelece padrões institucionalizados de valores culturais direcionados a determinados grupos, por considerá-los inferiores.

Fraser, no caso em tela, postula que se trata de um problema de status social e exemplifica resgatando a categoria do gênero, em que as mulheres são vistas como inferiores frente aos homens, tornando-se suscetíveis à exclusão social e à marginalização política, à negação dos direitos e às proteções iguais de cidadania. As injustiças decorrentes da subordinação de status só podem ser corrigidas pela política de reconhecimento que conduza não à essencialização da identidade, mas à sua desconstrução. (Fraser, 2003, p. 23).

Em Scales of Justice, Fraser (2010) modifica seu modelo bidimensional, introduzindo a dimensão do político. Tal mudança decorre da substituição de um modelo territorial/nacional de delimitação dos espaços (modelo Keynesiano Westfaliano) para um espaço global, sem delimitação de fronteiras (modelo pósWestfaliano), em que as questões atinentes ao primeiro modelo já não conseguem mais respostas suficientes em nível nacional, como refere Fraser (2009, p. 14), ao exemplificar a evolução de um modelo para o outro: "[...] muitos observam que os processos sociais que moldam suas vidas rotineiramente transbordam as fronteiras territoriais".

Em outras palavras, existe uma transformação na forma de reivindicar, já que em nível nacional, muitas vezes, as políticas já não atendem mais aos anseios contemporâneos dos movimentos sociais, como ocorre com o referido caso. Nesse diapasão, Fraser (2010, p. 18) indaga: “[...] as regras de decisão concedem à comunidade igual participação de todos os membros nas deliberações públicas e uma representação equitativa na adoção de decisões públicas?" Em resposta, assevera que essas questões são conceitualmente diversas da redistribuição e do reconhecimento, posto que a dimensão do político não pode se reduzir a essas duas esferas, embora esteja diretamente ligada a elas. Logo, é dessa coimbricação das esferas - pressuposta por Fraser (1999) que o monismo de Honneth não se faz plausível.

Contudo, a terceira dimensão da justiça também agrega como objetivo explicar as injustiças no plano metapolítico/global, que surgem quando se realiza a divisão do espaço político em sociedades delimitadas territorialmente. O resultado é a delimitação injusta da possibilidade de reivindicação das questões de primeira ordem - distribuição, reconhecimento e representação - inspirando injustiças de mau enquadramento. Por conseguinte, aqueles que se caracterizam como não membros são afastados do contexto daqueles merecedores de reconhecimento no interior da entidade política, no que diz respeito a questões de distribuição, de reconhecimento e de representação política ordinária. (Fraser, 2010). 
Para tanto, Fraser propõe uma estratégia de reflexão sobre o problema do enquadramento, recomendando que a teoria da justiça deve se tornar tridimensional para então apresentar sua nova dimensão: a política. Defende ainda que cabe compreender a dimensão política da representação como apropriada para englobar três níveis. (Fraser, 2009). Nessa senda, aponta como exemplo de injustiça de enquadramento, em nível transnacional, a globalização da pobreza que ultrapassa as fronteiras territoriais. Elenca, no mundo globalizado, três núcleos de anormalidade em relação à justiça social, refletindo-se em profundas divergências em torno desses núcleos principais, a saber, as questões de quem tem o direito de fazer reclamações de justiça em relação ao o quê. Por fim, surgem disputas em relação ao como. Em contextos anormais, o o quê da justiça simboliza objeto de disputa. Alguns criticam a injustiça distributiva, enquanto outros tematizam a subordinação de status. A seu turno, há atores sociais que vislumbram o domínio do político. (Fraser, 2010).

Com efeito, sinaliza como segundo núcleo de anormalidade que decorre da ausência da visão compartilhada sobre o quem da justiça. A questão é quem conta como sujeito da justiça, como merecedor de igual consideração. Na justiça normal, o quem da justiça é estabelecido pelos cidadãos de uma comunidade política delimitada territorialmente. No entanto, na justiça anormal, o quem não está definido. Surgem então diferentes enquadramentos de disputas jurídicas: enquanto uma parte define a questão em termos de um quem doméstico e territorial, outra propõe um quem regional, transnacional, global. (Fraser, 2010).

Por fim, o terceiro núcleo de anormalidade decorre da ausência da visão comum sobre o como. Ao reivindicarem o direito de determinar o quem, os movimentos sociais problematizam o como hegemônico. A má representação na política ordinária ocorre quando regras de uma entidade política quanto à tomada de decisões negam o direito de voz e de deliberação nos processos decisórios a indivíduos que já são membros daquela nação, que ficam impedidos de participar como iguais nas interações sociais. Aqui se verifica um déficit democrático alinhado ao entendimento de Fraser (2009). Cumpre salientar que

As lutas por justiça em um mundo globalizado não podem alcançar êxito se não caminharem juntamente com as lutas por democracia metapolitica. Então, nesse nível também, não há redistribuição ou reconhecimento sem representação. (FRASER, 2009, p. 34).

No momento em que se adota uma abordagem democrática do como, a teoria da justiça assume a forma adequada para um mundo globalizado, e o entendimento da justiça como paridade participativa acaba por conceder exatamente o modelo de reflexividade que é exigida no contexto transnacional. (Fraser, 2009). Em face dessa leitura, no trabalho de 2003 - intitulado Redistribution or Recognition: a Political-Philosophical Exchange, de autoria de Fraser (2003a; 2003b) e de Honneth (2003b; 2003c) - a teórica feminista desenvolve alguns exemplos para elucidar a questão. Um deles é a questão de gênero que, no contexto da obra, torna-se um problema de redistribuição (salários mais baixos, maior informalidade no labor, dentre outros) e de reconhecimento (abusos sexuais, violência doméstica, objetificação, negação de iguais direitos, dentre outros). 
Entretanto, Honneth (2003b), no contexto do dualismo de Fraser, ao criticar as duas primeiras dimensões de sua teoria, considera que as esferas do reconhecimento e da redistribuição não se complementam, haja vista que sempre que se estiver diante de um conflito, em sua origem, inevitavelmente se estará conectado à reivindicação por reconhecimento e à superação de um contexto de invisibilidade social.

Para Fraser (2003a; 2003b), Honneth (2003b), ao realizar a construção de uma teoria monista, não entende como necessária uma segunda ordem de reconhecimento, pois apenas uma explicação diferenciada acerca do reconhecimento é imperativa na teoria crítica. Aqui o reconhecimento configura uma categoria suficiente para identificar todos os déficits normativos da sociedade contemporânea. Em contraposição, Fraser (2003a; 2003b) desenvolve sua perspectiva dualista de reconhecimento e de redistribuição por entender que está limitada a uma forma de injustiça social e, assim, não se basta sozinha - como pretende Honneth (2003b). Portanto, suscita a dimensão da injustiça distributiva em que se incluem os mecanismos do mercado capitalista.

A perspectiva de uma única via culturalmente homogênea é difícil de ser considerada e tal visão acaba apelando para um viés sectário, que não seria desejável para a teoria de justiça. Portanto, o que a teoria crítica precisa é satisfazer duas condições ao mesmo tempo: ser geral - para evitar o sectarismo - e determinada, para julgar os conflitos. Somente assim e teoria pode fazer frente em problemáticas de nível global. (Fraser, 2003b).

Fraser (2003b) deixa claro que sua teoria é superior à de Honneth, e que, por trás de todos seus debates teóricos, o problema do filósofo é sempre o mesmo: "Honneth amplia em excesso a categoria do reconhecimento, até o ponto de perder sua força crítica”. (FRASER, 2003b, p. 151). Realmente, quando Honneth (2003c) rebate tais análises de Fraser, revela não acreditar nas críticas que lhe são dirigidas pela socióloga, chegando ao ponto de afirmar que seria necessário assumir uma postura ofensiva - e não mais defensiva - em sua réplica à Fraser.

Ainda em sua crítica, Fraser (2003b) explica, no âmbito do monismo moral de Honneth (2003b), que não é evidente que o descontentamento diário dos indivíduos dependa sempre da negação de reconhecimento. Dessa feita, ter apenas uma motivação na base dessa infelicidade seria, de alguma forma, inverossímil em sua perspectiva. A teórica do reconhecimento ainda insinua que contextos em que alguém é privado de certas possibilidades ou excluído socialmente por motivos de desigualdade econômica não seriam alcançados pela teoria de Honneth.

Tais questões negam a paridade de participação e, na concepção de Fraser (2003a; 2003b), considerar que contemplam violações da identidade pessoal não seria a melhor interpretação possível delas mesmas. Fraser (2003a; 2003b) considera então que, no âmbito da interpretação, acaba-se por centrar-se no eu - e não mais na sociedade, na qual se assenta um sentido personalizado do dano. Por fim, compreende que tais problemáticas exemplificadas devem ser tratadas como formas de injustiça sentidas, e não como um reconhecimento negado. Porém, realça que mais preocupante do que tal questão é a designação desse sofrimento como o ponto de 
referência privilegiado da teoria crítica. (Fraser, 2003b).

Honneth (2003b; 2003c) alega que Fraser (2003a; 2003b), desde o princípio da explicação de sua teoria, utiliza uma manobra para chegar ao dualismo de perspectiva preconcebida (redistribuição e reconhecimento), pois não comprova se haveria outras formas de reconhecimentos específicos em determinadas sociedades. Nesse ponto, a questão parece plausível, já que Fraser (2003a; 2003b) não traz comprovação do que postula Honneth (2003c). Todavia, mais tarde, Fraser (2010) elabora a sua terceira dimensão de reconhecimento, mostrando haver insuficiência nas duas esferas obtidas a princípio, e confirmando que é possível haver mais formas de reconhecimento criadas em conformidade com a demanda da evolução social.

Em se tratando da divisão de Fraser (2003a; 2003b) entre lutas por redistribuição e lutas por reconhecimento cultural, para Honneth (2003c), as primeiras decorrem da experiência do desrespeito e, portanto, pressupõem tentativas de estabelecer padrões valorativos que efetivamente avaliem de forma positiva as contribuições sociais dos indivíduos. Ademais, seria imprescindível a análise da gramática moral que estaria por trás de todos os conflitos sociais vivenciados.

Por conseguinte, no quadro teórico que se descortina, Honneth (2003a), em Luta por Reconhecimento, basicamente apura três formas de reconhecimento - a dedicação emotiva (o amor), o autorrespeito (o direito) e a estima social (solidariedade) - as quais correspondem a três formas de desrespeito, o que poderá acarretar o surgimento de conflitos sociais.

De fato, a criança, nos primeiros meses, percebe-se como parte da mãe, mas paulatinamente aprende a conceber-se como ser independente. E na medida em que a mãe, aos poucos, retorna às suas atividades cotidianas, como reação, o bebê para de rebelar-se contra essa independência e dirige contra ela atos agressivos. Nessa ótica, trata-se de uma luta por reconhecimento, porquanto "[...] só na tentativa de destruição da mãe, ou seja, na forma de uma luta, a criança vivencia o fato de que ela depende da atenção amorosa de uma pessoa, existindo independentemente dela, como um ser com pretensões próprias.” (HONNETH, 2003a, p. 170).

Nesse âmbito, cria-se "[...] a medida de autoconfiança individual, que é a base indispensável para a participação autônoma na vida pública." (HONNETH, 2003a p. 178). De acordo com Bunchaft (2014), Honneth (2003a) pondera que, após a evolução nos estudos psicanalíticos sobre o desenvolvimento da personalidade humana, "[...] seria intrínseco às relações afetivas entre mãe e filho uma articulação entre autonomia e ligação, porquanto, como leciona Hegel, o amor deve ser compreendido como 'um ser-si-mesmo em um outro'." (BUNCHAFT, 2014.p. 61)

Tal concepção é entendida pelo próprio doutrinador (2003a) como uma teoria pluralista (três princípios), em que se pode informar a análise das lutas e dos processos sociais de transformação com respeito aos quais podem considerar-se justificadas as reivindicações morais. Por outro lado, resgatando o pensamento de 
Winicott, Honneth (2003a) afasta-se das linhas psicanalíticas que designam a criança como objeto de investigação independente. Fundamentando-se em pressupostos intersubjetivos, concebe o amor como forma determinada de reconhecimento em virtude do modo específico pelo qual o sucesso "[...] das ligações afetivas se torna dependente da capacidade, adquirida na primeira infância, para o equilíbrio entre a simbiose e a autoafirmação" (HONNETH, 2003a, p. 163).

Contudo, mais importante do que a esfera é o reconhecimento dos cidadãos como sujeitos de direito. Apenas na medida em que direitos universais não são concedidos aos membros dos grupos sociais em razão do status - mas de forma igualitária a todos os seres humanos - que se possibilita assumir a ideia de autorrespeito. $\mathrm{Na}$ experiência do reconhecimento jurídico, surge a possibilidade da autocompreensão positiva em relação a si mesmo. Honneth (2003a) remete à luta do movimento negro por direitos civis na década de 1950 e de 1960 como expressão do "[...] significado psíquico que o reconhecimento jurídico possui para o autorrespeito dos grupos excluídos." (HONNETH, 2003a, p. 198)

Já a estima social diz respeito ao que diferencia o indivíduo dos demais sujeitos. Segundo Honneth (2003a), além de superadas as demandas atinentes à esfera do amor e à do direito, para o ser humano desenvolver a autorrelação intacta, calha a estima social que possibilite referir positivamente suas propriedades e suas capacidades concretas.

Em síntese, "[...] a estima social se aplica às propriedades particulares que caracterizam os seres humanos em suas diferenças pessoais." (HONNETH, 2003a, p. 210). Trata-se de um medium social que reflete as diferenças de propriedades entre os seres humanos de maneira intersubjetivamente vinculante. A estima assim se vincula ao contexto de vida social em que os membros contribuem para a efetivação de objetivos sociais em uma comunidade de valores. Nesse ponto de vista, o ser humano é mais ou menos estimado conforme suas capacidades possam - ou não - auxiliar a concretizar os objetivos de sua sociedade. Destarte, considera que

[...] sob condições das sociedades modernas, a solidariedade está ligada ao pressuposto das relações sociais de estima simétrica entre sujeitos individualizados (e autônomos); estimarse simetricamente nesse sentido significa considerar-se reciprocamente à luz de valores que fazem as capacidades e as propriedades do respectivo outro aparecer como significativas para a práxis comum. (HONNETH, 2003a, p. 210).

Convém mencionar que, quando grupos são excluídos do processo político, terminam por vivenciar uma experiência de desrespeito, que é a base motivacional dos conflitos sociais. Em concordância com Honneth (2003a), lutas por reconhecimento podem ser desencadeadas por motivos como sentimentos de vergonha e de desprezo. Entretanto, isso dependerá também da esfera social na qual os indivíduos estão inseridos.

Para se ter a capacidade de mobilizar os movimentos sociais, é necessário que a ofensa que atinge um indivíduo seja universalizável em uma linguagem comum, transformando-se em efetiva mobilização política. Com isso, tais sentimentos impedem as condições básicas para que se atinja a autorrealização plena. Segundo Honneth, 
Para chegar a uma autorrelação bem-sucedida, ele depende do reconhecimento intersubjetivo de suas capacidades e de suas realizações; se uma tal forma de assentimento social não ocorre em alguma etapa de seu desenvolvimento, abre-se na personalidade como que uma lacuna psíquica, na qual entram as reações emocionais negativas como a vergonha ou a ira. Daí a experiência do desrespeito estar sempre acompanhada de sentimentos afetivos que, em princípio, podem revelar ao indivíduo que determinadas formas de reconhecimento lhe são socialmente denegadas. (HONNETH, 2003a, p. 220).

É mister lecionar que Honneth resgata as ideias de Dewey, de acordo com o qual os sentimentos são percebidos como "[...] a repercussão afetiva do sucesso ou insucesso de nossas intenções práticas." (HONNETH 2003a, p. 221). Também é premente reiterar o conceito delineado por Honneth (2001) - o de invisibilidade social - o qual se reflete quando os parceiros de interação social não reconhecem singularidades, ou seja, ao não identificar as especificidades de cada um, terminam por assumi-los por invisíveis, como pessoas que não existem na sociedade.

Em suma, para Honneth (2001, p. 01), “[...] a história cultural oferece inúmeros exemplos nos quais o dominador expressa sua superioridade social ao não perceber aqueles que dominam." Um sujeito pode confirmar sua própria visibilidade somente forçando seu parceiro de interação social a reconhecer as singularidades e as propriedades que formam uma identidade.

Na reflexão sobre a forma de conceber o indivíduo em A Luta por Reconhecimento e em Direito da Liberdade, livro mais recente, Sobottka (2013) refere que, na primeira obra, a capacidade de o indivíduo autonomamente instituir e concretizar seu projeto de vida ainda era avaliada no nível de relações intersubjetivas diretas. Já no atual contexto, a mesma capacidade deverá ser avaliada no nível das principais instituições sociais.

Honneth (2015) procede referindo ser necessário analisar os diferentes modelos de liberdade individual, com o objetivo de selecionar aquele modelo através do qual cada concepção de justiça deverá se orientar. Nessa senda, toma três dimensões de liberdade - jurídica, moral e social.

Honneth (2015) aponta como um dos elementos fundamentais para a construção da esfera pública democrática a consagração do ideal do patriotismo constitucional que permita fluxos de comunicação entre governo e população. Para tanto, enumera cinco pressupostos que irão viabilizar maior nível de concretização da liberdade social: a) garantias jurídicas de participação política dos indivíduos; b) espaço comunicativo comum; c) sistema diferenciado de mídia; d) motivação para engajamento participativo dos cidadãos em discussões públicas; e e) cristalização do sentimento de solidariedade cívica. Tais pressupostos são fundamentais para a posterior análise dos votos dos Ministros do STF na ADI 4277.

Voltando à questão da terceira dimensão do reconhecimento em Fraser, que corresponde à esfera do político, também se conecta às outras, pois embora não se reduza à redistribuição e ao reconhecimento, também não pode ser vislumbrada de maneira desconectada. À vista disso, a teórica passa a defender a perspectiva 
tridimensional de justiça, que trata o reconhecimento, a redistribuição e a representação (esfera do político) como categorias analiticamente distintas, mas que estão interligadas e se reforçam mutuamente.

Fraser (2001) distingue remédios afirmativos e transformativos: os primeiros estão conectados ao "multiculturalismo dominante", em que advoga reparar o desrespeito por meio da reavaliação das identidades injustamente desvalorizadas de grupos, deixando intactos tanto o conteúdo dessas identidades, quanto as diferenciações de grupos que as embasam.

Diante dessa estrutura conceitual, Fraser (2003a) sustenta que o modelo de status permite a cada indivíduo justificar e tematizar pretensões por reconhecimento como moralmente vinculantes sob as condições modernas de pluralismo valorativo. Aduz ainda que a estratégia equivocada, vinculada à tentativa de justificação de demandas por reconhecimento identitárias relacionadas ao ideal da autorrealização, implica uma perspectiva sectária. Argumenta finalmente que o modelo de status é deontológico e não sectário, e "[...] não apela para uma concepção de autorrealização ou bem. Diferentemente, apela para a concepção de justiça que pode - e deve - ser aceita por aqueles com concepções divergentes de bem." (FRASER, 2003a, p. 31).

A leitura oportuniza compreender que a desvantagem do paradigma da autorrealização é a de que não vislumbra os padrões institucionalizados de valores culturais que inviabilizam aos indivíduos a possibilidade de tornarem-se parceiros plenos nas interações sociais e que impedem o ideal da paridade de participação.

Por sua vez, a estratégia teórica do modelo de status é adequada para as demandas dos grupos estigmatizados, pois visa combater leis matrimoniais que excluem parceiros do mesmo sexo e os concebem como ilegítimos e perversos. Tratam-se de políticas de bem-estar social que estigmatizam mães solteiras como parasitas sexualmente irresponsáveis, e "[...] práticas policiais tais como os perfis raciais que associam pessoas racializadas à criminalidade." (FRASER, 2003a, p. 29-30). Com efeito, para Fraser, “[...] em cada caso, o efeito é a criação de uma classe de pessoas desvalorizadas que se veem impedidas de participar como pares uns com os outros na vida social." (FRASER, 2003a, p. 29-30).

Diante dessa estrutura conceitual, a passagem supracitada só vem a corroborar o entendimento segundo o qual a visão de Fraser acerca do reconhecimento revela maior potencialidade em efetivar direitos de minorias estigmatizadas em nossa sociedade moderna, tendo em vista sua estrutura deontológica, que atende ao pressuposto do pluralismo. Fraser busca desenvolver o conceito de paridade de participação dentro do parâmetro da prioridade do justo sobre o bem, já que o princípio seria o grande objetivo da teoria da justiça.

Dessa feita, envolve a possibilidade de igual participação de todos os cidadãos como pares nas interações sociais, sem excluir ninguém em razão do não reconhecimento, da não distribuição ou da ausência de representação, o que acarretaria um ato de violação à justiça.

Fraser (2010) alerta para a necessidade de um princípio normativo que englobe as três dimensões da 
justiça e aponta que o mais adequado, para tanto, é a paridade de participação, pois os três tipos de injustiça (má distribuição, não reconhecimento e ausência de representação) violam um mesmo princípio.

Na concepção de Honneth (2003a), por sua vez, a estima social contempla um pressuposto para o desenvolvimento da intersubjetividade não distorcida, tendo em vista a formação de uma identidade positiva. Vale também frisar a concepção de Bunchaft (2014, p. 67) acerca das divergências dos estudiosos, que revela que

A divergência fundamental entre os autores consiste no seguinte pressuposto: para que se forma a identidade? Para Honneth, a possibilidade de desenvolvimento da identidade autônoma seria um fim em si mesmo, sendo que a participação na esfera pública assume uma dimensão instrumental; para Fraser, é um meio para alcançar o fim superior da participação.

Nesse panorama, Fraser (2003b), em seu debate com Honneth (2003a; 2003b), sustenta que seria relevante o que realmente conta a título de injustiça em contraposição ao que é meramente vivenciado como injustiça. Fraser alerta ainda que a injustiça do não reconhecimento independe da presença de efeitos psicológicos.

De fato, Fraser (2008) sugere que deveria se apelar não para a esfera de experiências subjetivas insuscetíveis de serem publicamente verificáveis, e sim, para impedimentos externamente manifestados e publicamente verificáveis que impossibilita alguns indivíduos de serem membros plenos da sociedade.

Mas não seria uma estratégia equivocada fazer apologia do sofrimento pré-político? Nesse sentido, Fraser (2008, p. 310-326) enfatiza que "[...] cada luta histórica contra injustiça tem envolvido a criação de novos vocabulários para articulação de injustiças que previamente são inominadas." A segunda fase do movimento feminista inovou com a criação de expressões como estupro, assédio sexual, dentre outras. Fraser relata que os contrapúblicos de resistência permitem aos movimentos sociais expandir a gama de conhecimento de injustiças publicamente articuladas, ampliando o universo da razão pública, por meio de formas críticas de comunicação expressas, em termos de "contrapúblicos", que são "[...] arenas discursivas paralelas nas quais os membros dos grupos socialmente subordinados inventam e circulam contradiscursos para formular interpretações opostas de suas identidades, interesses e necessidades." (FRASER, 1992, p. 123).

Em resumo, essa pluralidade de públicos concorrentes revelaria maior potencialidade para inspirar o princípio da paridade de participação, diferentemente de um público único, compreensivo. Por meio da noção de contrapúblico, "Fraser desenvolve uma ideia mais dinâmica de lutas sociais ao mesmo tempo em que acrescenta uma dimensão mais política à noção de esfera pública." (LARA; FINE 2007, p. 38). Ademais, de acordo com Bunchaft (2014), Fraser pretende demonstrar como em processos discursivos da esfera pública os grupos sociais com desigualdade de poder tendem a desenvolver estilos culturais desigualmente valorados. Com base em Fraser, conclui-se pela necessidade de desconstruir a dicotomia hétero-homo, desestabilizando as identidades sexuais, o que somente se efetivaria por meio da constatação de certos públicos alternativos que inspiram a circulação de discursos de oposição de grupos excluídos da esfera pública oficial - como por exemplo, transexuais e travestis. 
Não obstante, para Honneth (2003b), Fraser (2003a) não explica o que conduz os indivíduos a se mobilizarem e a se engajarem democraticamente em procedimentos com vistas à modificação das normas que regulam as interações sociais. Como não esclarecia a base motivacional dos conflitos sociais, sua teoria era incapaz de perceber a tendência à emancipação do real. Fraser (2003b), a seu turno, destaca que Honneth (2003a) não aborda adequadamente as relações de poder que surgem nas relações sociais. Não há nexo necessário entre o sentimento de desrespeito e a superação da dominação. Muitas vezes, relações de reconhecimento que são perpassadas por estruturas de poder, embora estabeleçam assimetrias, podem inspirar nos sujeitos um contexto de felicidade ilusória. A questão fundamental não é abordar o sentimento de desrespeito, mas os reflexos do não reconhecimento na esfera das interações sociais.

$\mathrm{Na}$ visão do filósofo, uma sociedade apenas é justa quando possibilita a seus membros o desenvolvimento de uma identidade intacta - o que para ele é o elemento fundamental de uma Teoria da Justiça sensível às vulnerabilidades dos indivíduos. Assim, conforme Fraser (2003b, p. 169), Honneth considera que “[...] toda reivindicação autêntica de justiça é uma reivindicação de reconhecimento, que aspira a consolidar uma identidade intacta. E toda reivindicação de reconhecimento está teleologicamente justificada, como meio para a vida boa. [...]"

Ou seja, tal concepção de justiça de Honneth (2003a; 2003b; 2003c) baseia-se em um viés teleológico de vida boa, em que busca-se alcançar uma identidade intacta. A ideia parece um tanto quanto paradoxal, visto que não se vislumbra como seria possível a todos os cidadãos alcançar uma identidade intacta, tendo em conta as especificidades de cada população, a crescente globalização e o pluralismo das sociedades contemporâneas, dentre outros fatores. Para Fraser (2003b, p.169), tal teoria é "deficiente como uma teoria de justiça." Ainda,

Quando fala de três princípios "igualmente importantes" de reconhecimento, não nos diz o que devemos fazer para que a estima das contribuições do trabalho de alguns suponha a negociação da igual cidadania de outros. A falta de um método para resolver estes conflitos, seu monismo tripartite de reconhecimento cai preso em outra dimensão de indeterminação. (FRASER, 2003b, p. 171).

A crítica de Fraser (2003a; 2003b) é de grande importância, tendo em vista que traz um dos pontos mais controversos da doutrina de Honneth (2003a; 2003b; 2003c), que requer igual cidadania a todos, mas não especifica como. Assim, se coloca a questão: como resolver tal impasse diante de um parodoxo de igualdade para alguns e de desigualdade/sofrimento para outros? Sua teoria não resolve a problemática e não soluciona a questão do escravo-feliz. Na perspectiva de Fraser (2003a; 2003b), o problema reside na questão do ponto de partida teleológico de Honneth (2003a; 2003b, 2003c), que acaba por assumir uma concepção de justiça através de uma ideia de vida boa e, assim, se vê compelido a dar passos extraordinários para evitar capitular diante do sectarismo ético, e tentando evitá-lo, acaba sucumbindo através da indeterminação. (Fraser, 2003b). Ou seja, acaba adotando uma perspectiva sectária e indeterminada, o que na visão de Fraser é inviável para uma teoria da justiça. 
Fraser (2003b) apresenta então o que seria a sua solução para tal impasse: uma teoria que pressupõe a concepção de autonomia e o valor moral igual dos seres humanos através de uma visão deontológica. Refere que apenas por esse viés poder-se-á articular as consequências da igualdade de autonomia por meio de uma teoria da justiça que seja compatível com uma pluralidade de visões razoáveis de vida boa. O princípio fundamental dessa teoria é a paridade de participação - que é deontológico, porém não é sectário. Portanto, tal princípio "[...] assume tanto a razoabilidade do desacordo ético como a igualdade de valor moral dos seres humanos", ainda afirmando que a paridade de participação "[...] é compatível com todas as formas de entender a vida boa que respeitem a igualdade de autonomia." (FRASER, 2003b, p. 172). O ponto principal desse ideal é que o princípio de paridade de participação sustenta que "[...] para respeitar a igualdade de autonomia e de valor moral dos demais, é preciso conceder-lhes o status de participantes de pleno direito na interação social." (FRASER, 2003b, p. 172).

Outra característica é que esse princípio apenas pode se dar de forma dialógica por meio do processo democrático de debates públicos (Fraser, 2003b), ou seja, é aplicável em sociedades democráticas que tenham por objetivo possibilitar a paridade de participação de todos os indivíduos, pois assim pode-se alcançar o consenso legítimo, uma vez que todos participaram da escolha com suas concepções de vida boa. Por fim, Fraser (2003b) compara seu ideal de paridade participativa com o projeto teórico de Honneth (2003a; 2003b) acerca da igualdade, e assim, diz que

[..] ao contrário de Honneth, meu enfoque não requer uma explicação ética dos tipos de participação que fazem falta para o progresso humano. Diferentemente, assume que os participantes o decidirão por si mesmos, a seu bem saber e entender. (FRASER, 2003b, p. 174).

Fraser (2003b) finaliza o enfoque que teoriza - a teoria deontológica, não sectária, determinada especificando que é suficiente para satisfazer aos requisitos de uma teoria crítica da justiça em uma era de globalização.

Portanto, com a abordagem das perspectivas de Honneth (2003a; 2003b; 2003c; 2015) e de Fraser (2003a; 2003b; 2010) acerca da concepção de reconhecimento, objetiva-se esclarecer a pergunta: o reconhecimento é uma questão de justiça (Fraser) ou de autorrealização (Honneth)? A indagação representa um ponto de grande divergência entre ambos, uma vez que Honneth (2003a; 2003b; 2003c; 2015) trata o reconhecimento como categoria da sociologia e da psicologia moral ligada à ideia de autorrealização individual, e por outro lado, Fraser (2003a; 2003b; 2010) compreende o reconhecimento como uma questão essencialmente de justiça, o que não configura obstáculo para a autorrealização, atendo-se às práticas discriminatórias institucionalizadas que acarretam a violação à justiça.

Indubitavelmente, Fraser (2003a; 2003b; 2010) explicita uma visão mais profunda e abrangente acerca do reconhecimento/não reconhecimento, pois não se abstém a entender o último apenas como deformação 
psíquica capaz de inspirar sentimentos de vexação, mas vai além, trabalhando com práticas discriminatórias institucionalizadas e com a ideia de paridade de participação. O não reconhecimento, na concepção de Fraser, surge quando há institucionalização de padrões de valores culturais que impedem a paridade de participação.

Em debate com Fraser (2003a; 2003b), no livro Redistribution or Recognition: A Political Exchange, Honneth (2003b) em resposta à crítica direcionada ao âmbito da Psicologia Moral, ressalta que ela dramatiza demais a questão, já que as considerações da psicologia moral sobre a fundação do reconhecimento apenas exercem papel da concepção de justiça na medida em que apoiam a tese teórico-social de que a integração social impregna as forma de reconhecimento mútuo. Além do mais, afirma que a tese de Teoria Social, em vez da Psicologia Moral, simboliza a chave para determinar a finalidade da justiça social.

Em consonância com a concepção de Honneth (2003b), depreende-se que é apenas em condições de estabelecimento de uma ordem social que os indivíduos podem atingir uma autorrelação possível consigo mesmos - portanto, que inspire a autonomia individual. O filósofo preocupa-se com a dialética moral dos conflitos e com a psicologia do sofrimento pré-político. Atribui ênfase ao sofrimento e aos sentimentos de vexação que antecedem os conflitos, realçando que todos os conflitos sociais têm como base a experiência de injustiça. Por sua vez, Fraser (2003a; 2003b; 2003c) abraça a ideia de que o reconhecimento abarca uma questão de justiça social.

Nessa senda, Fraser (2003b) afirma que Honneth (2003a; 2003b; 2003c), ao abordar que a Psicologia Moral trata como única experiência autêntica de injustiça a depreciação da identidade, acaba por reduzir todas as demais injustiças a tal perspectiva. Institui então uma construção tradicional fundamentalista, em cuja base está a psicologia moral. Na concepção de Fraser, tal teorização acaba por "[...] restringir de forma indevida a sociologia política, a teoria social e a filosofia moral, truncando de forma ilegítima essas investigações e quebrando sua relativa autonomia." (FRASER, 2003b, p. 155).

Fraser assinala também que "[...] na teoria moral, podemos identificar normas para julgar as reivindicações de justiça, sem estar limitados pelos ditados de uma psicologia imperfeita." (FRASER, 2003b, p. 157). Sob esse prisma, em conformidade com Bunchaft (2014), Fraser distancia-se da abordagem psicológica do reconhecimento, opondo-se à desconexão entre as dimensões econômica e cultural e distanciando-se da perspectiva dicotômica que atribui ênfase às questões de justiça material ou que se restringe às injustiças culturais.

A divisão social entre homossexuais e heterossexuais, por exemplo, não se fundamenta somente em critérios econômicos, visto que os homossexuais ocupam diferentes posições sociais na divisão do trabalho e não constituem uma classe especialmente explorada. Assim, Fraser vê a divisão enraizada diferentemente na ordem de status da sociedade como padrões institucionalizados de valores culturais, que estabelecem a heterossexualidade como natural e normativa, e a homossexualidade como perversa e desprezada. Nesse aspecto, é clara a afirmativa 
de Fraser (2003, p. 18), ao descrever que:

Eles estão também estabelecidos em muitas áreas da política governamental (incluindo imigração, naturalização e política de asilo) e padrões de práticas profissionais (incluindo medicina e psicoterapia). Padrões valorativos heteronormativos também penetram na cultura popular e na interação cotidiana. $O$ resultado é construir gays e lésbicas como uma sexualidade desprezada, sujeitos a formas sexualmente específicas de subordinação de status. $\mathrm{O}$ último inclui vergonha e assalto, exclusão dos direitos e privilégios do casamento e parentesco, restrições nos direitos de expressão e associação, imagens estereotipadas danosas na mídia, assédio e depreciação na vida cotidiana e negação dos plenos direitos e de igual proteção da cidadania.

Para Fraser (2003a), combater a homofobia e o heterossexismo requer a modificação da ordem sexual de status, desinstitucionalizando padrões de valores culturais heteronormativos e substituindo-os por outros, que expressem igual respeito por gays e por lésbicas. Em relação às classes sociais nas quais os sujeitos são tradicionalmente explorados, há necessidade de remédios redistributivos que visem superar injustiças econômicas.

Assim, entende-se que somente a criação de novos contrapúblicos subalternos que ampliam novas interpretações de necessidades não ouvidas na esfera pública oficial torna possível combater a inexpressividade ou a ausência de voz. Nesse particular, o modelo de status desenhado por Fraser é deontológico e não apela para a concepção de autorrealização ou de bem, mas para a concepção de justiça democraticamente estabelecida, que pode ser aceita e justificada por concepções divergentes de bem.

Em suma, Fraser enfatiza o reconhecimento na melhor das perspectivas possíveis, posto que o vê como questão unicamente de justiça social e sob a perspectiva tridimensional - e não apenas como questão de autorrealização. E vai além: não trabalha com as práticas depreciatórias ou com o sofrimento inarticulado de que trata Honneth, mas com as práticas discriminatórias institucionalizadas que estabelecem a subordinação de status. Portanto, sua teoria é mais abrangente, aplicando-se de maneira mais pertinente e revelando maior alcance para casos de não reconhecimento de minorias sexuais.

\section{A ADI-DF 4.277/ADPF-RJ 132: ANÁLISE DO CONTEÚDO DOS VOTOS DOS MINISTROS DO STF A LUZ DA TEORIA DO RECONHECIMENTO DE FRASER E DE HONNETH}

Após anos de luta pelo reconhecimento do casamento gay, começaram a surgir sinais de que havia esperança para a efetivação da igualdade entre os direitos das minorias gays e dos casais heterossexuais. Os casais homossexuais ainda constituem uma minoria sexual estigmatizada que vem enfrentando obstáculos no processo político majoritário, tanto no que se refere ao casamento civil igualitário, como no que tange à criminalização da 
homofobia. Porém, no ano de 2011, o STF deu um passo proveitoso, decidindo pela possibilidade do reconhecimento da união estável entre pessoas do mesmo sexo no julgamento da ADI 4277-DF.

Nessa decisão, decidiu-se ainda que o art. 1723 do Código Civil Brasileiro - que trata da união estável fosse aplicado em consonância ao parágrafo $3^{\circ}$ do art. 226 da Constituição Federal, de forma que os casais homossexuais teriam a possibilidade de constituírem formalmente a união estável.

Subsequentemente à breve exposição do direito ao reconhecimento, adentra-se na decisão do STF relativa à ADI 4277/ADPF n. 132. Uma das questões que mais se discutiu em torno da decisão do STF é o conceito da ideia de família. Os Ministros Ayres Brito, Luiz Fux e Ricardo Lewandowski - ainda que este último, de forma mais tímida - fizeram referência em seus votos às novas concepções de família da sociedade contemporânea. Portanto, nesse sentido, acabou-se por considerar a união homoafetiva como a constituição de uma família.

Destarte, o voto do Ministro Carlos Ayres (BRASIL, 2011a) consagrou um conceito renovado de família, ampliando a concepção tradicional por meio da interpretação sistemática e da ênfase ao princípio da Unidade, que pretende interpretar a Constituição na sua totalidade. De fato, o artigo $226, \$ 3 .^{\circ}$, foi interpretado pelo STF de maneira articulada com os Princípios da Dignidade da Pessoa Humana: liberdade, legalidade, igualdade.

A Constituição Federal, o Direito Civil e as demais normas foram criados para atender ao conceito tradicional de família, embora hoje já não sejam suficientes para acolher as novas demandas que surgem. Portanto, insta a ruptura com as concepções assimétricas de mundo - o que paulatinamente vem ocorrendo. A partir dessas transformações, o Direito vai se moldando à nova dinâmica social apresentada, atendendo ao pluralismo que marca a sociedade. Para finalizar a discussão, tem-se que, na ordem democrática em que se vive, a discriminação sexual é juridicamente ilícita. (LOPES, 2011).

A concepção tradicional de família no direito pátrio tem passado por transformações de grande alcance, desde a decisão do STF na ADI 4277-DF, culminando com a edição da Resolução 175 do CNJ. A omissão legislativa na efetivação dos direitos de casais homossexuais legitimou tanto a decisão do STF no julgamento da ADI 4277-DF em 2011, quanto à edição da Resolução 175 do CNJ, a qual dispõe sobre habilitação, celebração de casamento civil ou conversão de união estável em casamento entre pessoas do mesmo sexo, instaurando que os Cartórios Extrajudiciais brasileiros devem assim proceder, sem criar obstáculos a quem pretenda legitimar os atos jurídicos elencados.

Os Ministros Ricardo Lewandowski, Gilmar Mendes e Cesar Peluso, embora considerando a pretensão procedente, assentaram a existência de lacuna normativa sobre a questão. Convém mencionar que a estrutura sexual binária repercutiu no voto do Ministro Gilmar Mendes, quando defendeu que a aplicação da analogia 
decorreria da similitude factual entre união estável e a homoafetiva, não incidindo todas as normas relativas àquela entidade, porquanto não se trataria de equiparação. (BRASIL, 2011b).

Dessa feita, o Ministro Gilmar Mendes limitou-se a reconhecer a existência dessa união pelo mecanismo da analogia ou, na falta de outra possibilidade, pela interpretação extensiva da cláusula do art. 226, parágrafo $3^{\circ} \mathrm{da}$ Constituição Federal (BRASIL, 1988), sem se pronunciar sobre outros desdobramentos. Consagrou ainda que a ideia de opção sexual estaria contemplada no exercício do direito de liberdade, realçando que a ausência de um modelo institucional que garantisse a proteção dos direitos fundamentais em apreço contribuiria para a discriminação. (BRASIL, 2011b).

O Ministro Luiz Fux, por sua vez, ponderou que as uniões homoafetivas em nada se diferenciam das uniões estáveis heterossexuais, concebendo-as como entidades familiares simétricas. Portanto, estariam incluídas no conceito constitucional de família, porquanto qualquer distinção entre uniões homossexuais e heterossexuais violaria a isonomia. Resgatou também a ideia de política de reconhecimento, por "admitir a diferença entre os indivíduos e trazer para a luz relações pessoais básicas de um segmento da sociedade que vive parte importantíssima de sua vida na sombra." (BRASIL, 2011c, p. 70).

Por fim, o Ministro Luiz Fux suscitou a temática da segurança jurídica, a qual seria inspirada pelo reconhecimento das uniões homoafetivas como uniões estáveis, afastando incertezas e gerando previsibilidade. Assim como o Ministro-Relator, entendeu que não haveria impedimento à equiparação em razão do dispositivo literal homem e mulher. Na sua interpretação, o dispositivo foi inserido para conferir proteção constitucional às uniões estáveis, para retirá-las da marginalidade e para inclú́-las no conceito de família. Em síntese, sua estratégia argumentativa contribuiu para eliminar a subordinação de status dos casais homossexuais. (BRASIL, 2011c).

A Ministra Carmem Lúcia acompanhou o voto dos Ministros Carlos Ayres de Brito e Luiz Fux, realçando que "[...] todas as formas de preconceito merecem repúdio de todas as pessoas que se comprometem com a justiça, com a democracia, mais ainda os juízes do Estado Democrático de Direito”. (BRASIL, 2011d, p. 90).

O Ministro Joaquim Barbosa, a seu turno, julgou procedentes as duas ações constitucionais, mas divergiu da estratégia argumentativa dos outros Ministros. Resgatando a doutrina anglo-saxônica, postulou que o fundamento constitucional para o reconhecimento das uniões homoafetivas, em vez de se situar no art. 226, parágrafo $3^{\circ}$, localiza-se em todos os dispositivos da Constituição que tratam dos direitos fundamentais. (BRASIL, 2011e).

A Ministra Ellen Gracie acompanhou integralmente o voto do Ministro-Relator, tematizando a evolução dos direitos dos homossexuais e explicitando a trajetória de efetivação de seus direitos desde a descriminalização da sodomia até o reconhecimento das famílias homoafetivas na Espanha, em Portugal e na Argentina. Resgatou o 
caminho de consagração de direitos e de reconhecimento do casamento civil homoafetivo nos processos judiciais de países como Canadá e África do Sul. (BRASIL, 2011f).

Os votos de Ellen Gracie, de Celso Mello e de Marco Aurelio contêm um conjunto de discursos implícitos que afirmam o paradigma da autorrealização, desvinculando-se da ideia democrática de paridade de participação delineada por Fraser. Nessa perspectiva, contrapondo-se às formas de discriminação e de preconceito, enfatizou Ellen Gracie que "[...] uma sociedade decente é uma sociedade que não humilha seus integrantes." (BRASIL, 2011f, p. 1).

Fraser (2007) registra que, ao interpretar o não reconhecimento como uma depreciação à identidade, o modelo de Honneth destaca a estrutura psíquica, minimizando as instituições sociais e a interação social. Em verdade, uma sociedade justa - vale aqui dizer - é aquela em que os homossexuais não sofrem subordinação social no sentido de não serem impedidos de participar como pares na vida social.

Por sua vez, Celso Mello defende a relevância dos princípios da liberdade, da igualdade, da dignidade e do princípio constitucional implícito que consagra o direito à busca da felicidade, ao raciocinar que

[...] esta decisão que torna efetivo o principio da igualdade, que assegura respeito à liberdade pessoal e à autonomia individual, que confere primazia a dignidade da pessoa humana e que, rompendo paradigmas históricos e culturais, remove obstáculos que, até agora, inviabilizavam a busca da felicidade por parte de homossexuais vítimas de tratamento discriminatório [...].(BRASIL, 2011, g, p. 228.).

Os Ministros Marco Aurélio, Luiz Fux, Lewandowski também fizeram referência à concepção de busca da felicidade. Ayres Brito fez referência à ideia de "aplainar o caminho da felicidade". Ao invocar a busca da felicidade, minimiza-se que inexiste uma única concepção de vida boa que seja universalmente compartilhada. Assim, "[...] qualquer tentativa de justificar as reivindicações por reconhecimento que recorra a um relato de vida boa, deve, necessariamente, ser sectária." (FRASER, 2007, p. 121).

Com a mesma argumentatividade implícita, o Ministro Marco Aurélio também invocou julgado da Corte Interamericana de Direitos Humanos quanto à proteção jurídica do projeto de vida, que integraria o núcleo existencial do princípio da dignidade da pessoa humana. Considerou como núcleo do princípio da dignidade da pessoa humana a proibição à instrumentalização. Sob esse prisma, ao afirmar ser papel do Estado auxiliar os indivíduos para a realização dos respectivos projetos de vida, se afasta de uma perspectiva deontológica e consagra a ideia de liberdade social.

Como já salientado, para Honneth (2015), o papel da justiça é efetivar os pressupostos legais, políticos e sociais para a autorrealização individual. A liberdade dos casais homossexuais se concretiza no interior de práticas institucionalizadas que orientam seus objetivos.

A estratégia argumentativa dos Ministros Ellen Gracie, Marco Aurélio e Celso Mello é teleológica e suscetível a críticas, pois cria espaço para que surjam argumentos contrários invocando também a vulnerabilidade 
moral de grupos religiosos fundamentalistas. Diferentemente, o modelo de status defendido por Fraser recorre a uma concepção de justiça que deve ser aceita por indivíduos com diferentes concepções de vida boa.

Em suma, reitera-se que a ausência de inexpressividade ou de voz - a que se refere Honneth, em sua apologia do sofrimento pré-político - não evidencia alcance teórico para desestabilizar o binarismo sexual. Em relação ao argumento da laicidade do Estado, o Ministro Marco Aurélio elegeu a necessidade de separação entre conceitos morais religiosos e a outorga de direitos civis. É clara a assertiva do Ministro:

As garantias de liberdade religiosa e do Estado laico impedem que concepções morais religiosas guiem o tratamento estatal dispensado aos direitos fundamentais, tais como o direito à dignidade da pessoa humana, o direito à autodeterminação, o direito à privacidade $\mathrm{e}$ o direito à liberdade de orientação sexual. A ausência de aprovação dos diversos projetos de lei que encampam a tese sustentada pelo requerente, descontada a morosidade na tramitação, indica a falta de vontade coletiva quanto à tutela jurídica das uniões homoafetivas. As demonstrações públicas e privadas de preconceito em relação à orientação sexual, tão comuns em noticiários, revelam a dimensão do problema. (BRASIL, 2011, h, p. 205).

Embora o Brasil seja um país laico, o fundamentalismo religioso perpassa os avanços dos direitos dos casais homossexuais, especificamente nas tramitações de projetos normativos. Ademais, é essencial também a presença de um Judiciário comprometido com as demandas radicais de uma esfera pública transnacional em um contexto pós-Westfaliano.

Os Ministros Celso Mello e Luiz Fux, pressupondo o art. 226, parágrafo $3^{\circ}$ como norma de inclusão, consideraram a união estável homoafetiva como entidade familiar. Nas palavras de Fux, "[...] seria perverso conferir a norma de cunho indiscutivelmente emancipatório, interpretação restritiva a ponto de concluir que nela existe impeditivo à legitimação jurídica das uniões homoafetivas" (BRASIL, 2011d). O Ministro Fux votou pela procedência das duas ações, com a aplicação da técnica da interpretação conforme a Constituição ao 1723.

O Ministro Ricardo Lewandowski, por sua vez, enfatizou que a união homoafetiva não constitui união estável - que impõe gêneros diferentes - mas a forma distinta de entidade familiar não prevista no rol exemplificativo do art. 226 da Constituição Federal. (BRASIL, 1988). Com isso, o voto do Ministro ainda contempla uma interpretação binária de sexo. Nesse ponto, considerou cabível o mecanismo da integração analógica com o objetivo de aplicar às uniões homoafetivas as prescrições legais atinentes às uniões estáveis, excluindo-se aquelas que exijam diversidade de sexo para seu exercício até que o Congresso Nacional estabeleça tratamento legislativo. (BRASIL, 2011i).

Nessa perspectiva, sustenta-se que Lewandowski embora tenha julgado procedentes as ações, não apenas consagrou o binarismo sexual nocivo à paridade de participação, mas relegou as uniões homoafetivas a um limbo jurídico, incompatível com a proposta de Fraser.

E, indubitavelmente, tal estratégia argumentativa ainda consagrou a subordinação de status que 
inviabilizava o reconhecimento dos casais homossexuais como parceiros plenos nas interações sociais. Ora, o conceito de família não poderia ser interpretado de forma estática pelo Poder Judiciário, que deve estar aberto aos influxos hermenêuticos da sociedade civil e dos movimentos sociais.

Já, no voto do Ministro-Relator Carlos Ayres de Brito, partindo de uma perspectiva maximalista, ponderou que o tratamento discriminatório - ou preconceituoso - em razão do sexo dos seres humanos se contrapõe ao objetivo constitucional de promover o bem de todos. Enfatiza ainda a importância do pluralismo sociopolítico cultural como valor do preâmbulo da Constituição e um dos fundamentos da República Federativa do Brasil. Tal pluralismo sociopolítico-cultural, no entendimento do Ministro-Relator, estaria ligado à democracia substancialista baseada na respeitosa convivência dos contrários. (BRASIL, STF, 2011a).

Nesse ponto, o contato paritário entre as identidades - decorrente do pluralismo sociopolítico cultural e do Constitucionalismo Fraternal, como refere o Ministro - é fundamental para inspirar o sentido de solidariedade cívica, que é pressuposto para a ideia de liberdade social descrita por Honneth.

Como já se salientou, Honneth, em El derecho de la Libertad, elenca cinco pressupostos que irão viabilizar maior nível de concretização da liberdade social - dentre os quais, a cristalização do sentimento de solidariedade cívica. Portanto, o argumento do pluralismo é essencial para o estabelecimento de relações humanas ricas e plurais, mas, por outro lado, deveria ser aprimorado em direção à interpretação desconstrutiva capaz de contemplar a crítica ao binarismo sexual.

Honneth (2015) reconstrói as diversas formas de relacionamentos pessoais que envolvem a amizade, as relações íntimas e a família. Na obra, demonstra a evolução do amor romântico ao amor livre da década de 1970 e revela como a família patriarcal foi substituída pela família nuclear tradicional (em que os pais cumprem determinados papéis) que, por sua vez, evolui na direção da família moderna, na qual inexiste rigidez na divisão de papéis. Por fim, destaca como surgiram novas formas familiares compostas também por pessoas do mesmo gênero. Trata-se de vínculos mantidos por laços afetivos, enquanto tal modificação da autocompreensão institucional da família atingiu o aumento da liberdade.

A compreensão sobre a evolução institucional da família contém fundamentação filosófica baseada na ideia de liberdade social, o que a torna capaz de elucidar um conjunto de discursos implícitos ao voto do MinistroRelator, especificamente quando ressalta que a Constituição, ao fazer referência à instituição da família, para fins de especial proteção estatal, o fez "[...] em seu coloquial significado de núcleo doméstico, pouco importando se formal ou informalmente constituída, ou se integrada por casais heterossexuais ou por pessoas assumidamente homoafetivas." (BRASIL, STF, 2011).

Por meio de argumentos amplos e profundos, o Ministro-Relator depreendeu que a Constituição não vinculou a formação da família a casais heteroafetivos nem a qualquer formalidade cartorária, celebração civil ou 
liturgia religiosa. Interpretando o artigo 226 da Constituição Federal, menciona que a família é "[...] vocacionalmente amorosa, parental e protetora dos respectivos membros, constituindo-se no espaço ideal das mais duradouras, afetivas, solidárias ou espiritualizadas relações humanas de índole privada." (BRASIL, STF, 2011a).

Embora seu voto assuma conotação positiva e maximalista, ao afirmar que o preconceito em razão do sexo seria vedado constitucionalmente (já que a Constituição não obrigou, nem proibiu o uso concreto da sexualidade), ainda pressupõe a estrutura binária de sexo, quando narra que “[...] o sexo das pessoas, salvo expressa disposição constitucional em contrário, não se presta como fator de desigualação jurídica." (BRASIL, STF, 2011)

O Ministro-Relator deslinda expressamente que o sexo "[...] é um dado empírico que nada tem a ver com merecimento ou desmerecimento inato das pessoas, pois se não é mais digno ou menos digno pelo fato de se ter nascido mulher ou homem." Em outras palavras, presume o sexo como "[...] conformação anátomo-fisiológica", sendo biologicamente determinado. Assim, infere-se que a estratégia argumentativa ainda consagra a interpretação binária do sexo - que é problematizada por Fraser - estando implícita no julgamento, especialmente no voto do Ministro-Relator.

Destarte, ainda o Ministro-Relator defende o Constitucionalismo Fraternal voltado para a integração comunitária das pessoas, a se viabilizar por "[...] políticas públicas afirmativas da fundamental igualdade civil-moral (mais que simplesmente econômico-social) dos estratos sociais desfavorecidos e até vilipendiados." (BRASIL, 2011a). Fraser (2003), em sua crítica aos remédios afirmativos, assevera que, embora voltados a reparar a injustiça contra homossexuais na cultura contemplando a valorização da cultura LGBT, inspiram a reificação identitária, enquanto deixam intacto o código binário homem-mulher, hétero-homo (o que atribui sentido à relação).

É precisamente nesse sentido que aponta remédios transformativos conectados à pretensão de desconstrução, os quais modificariam a estrutura cultural subjacente, desestabilizando as diferenciações de grupo existentes, vinculados à queer politics - o que visa desconstruir a oposição homo-hétero, evitando a essencialização da identidade gay. A estratégia transformativa "[...] não é solidificar uma identidade gay, mas desconstruir a dicotomia hétero-homo a fim de desestabilizar todas as identidades sexuais." (FRASER, 2001.p. 268)

Acerca da hipótese prevista em tal trabalho, pode-se aduzir que a perspectiva de Fraser é a mais adequada para trabalhar a temática da concretização dos direitos das minorias gays e lésbicas no STF, pois contemplam grupos excluídos do processo político e que, aos poucos, vão ganhando reconhecimento e alcançando a paridade de participação proposta pela doutrinadora. Logo, ao analisarem-se os direitos das minorias sexuais, advoga-se que o direito ao reconhecimento de sua condição como parceira nas interações sociais é ponto crucial para a garantia de sua dignidade humana. Quando proferido pelo STF o julgado que reconheceu a possibilidade de união estável entre pessoas do mesmo sexo, verificou-se o início de um longo processo de reconhecimento dessa minoria. 
Com isso, compreende-se que Honneth e Fraser, apesar de trabalharem acerca da mesma temática (reconhecimento), tratam suas abordagens diferentemente: enquanto Honneth vê o reconhecimento como uma forma de autorrealização, Fraser pressupõe que se trata de uma questão de justiça social e que reflete uma dimensão tridimensional voltada para atingir a paridade de participação entre todos os membros da sociedade. Além do mais, Fraser trabalha o reconhecimento na melhor das perspectivas possíveis, já que o encara como uma questão unicamente de justiça social e sob o ponto de vista tridimensional, e não apenas como questão de autorrealização.

Fraser vai além: não trabalha com as práticas depreciatórias ou com o sofrimento inarticulado de que trata Honneth, mas com as práticas discriminatórias institucionalizadas que estabelecem a subordinação de status. Portanto, sua teoria é mais abrangente, aplicando-se de maneira mais pertinente e revelando maior alcance para casos de não reconhecimento de minorias sexuais. Diante dessa estrutura conceitual, são plenamente legítimas as decisões do STF nos julgamentos da ADI 4277-DF e ADPF 132-RJ, que se revelam capazes de atribuir a paridade de participação a um grupo minoritário até então estigmatizado e com déficit de representação no processo político majoritário.

\section{CONCLUSÃO}

Diante do que se explanou, é possível concluir que o voto do Ministro Carlos Ayres consagrou um conceito renovado de família, ampliando a concepção tradicional por meio da interpretação sistemática e contemplando implicitamente o princípio da Unidade, que pretende interpretar a Constituição na sua totalidade. Por conseguinte, o art. 226, $\$ 3^{\circ}$, estabelecido na Constituição Federal foi considerado pelo STF como articulado com os Princípios da Dignidade da Pessoa Humana (liberdade, legalidade, igualdade).

Todavia, interpreta-se, à luz da estrutura deontológica de Fraser (2010), que o referido Constitucionalismo Fraternal (mencionado pelo Ministro-Relator) se vincularia a remédios afirmativos, e não transformativos, sendo os primeiros insuscetíveis de desestabilizar a estrutura sexual binária. Com essa estrutura conceitual, o aporte teórico de Fraser - especificamente, sua concepção de remédios transformativos - é crucial para compreender e criticar um conjunto de discursos implícitos ao teor do voto do Ministro Carlos Ayres de Brito, precisamente pelo fato de a estudiosa defender a necessidade de desconstrução das dicotomias héterohomo e homem-mulher.

Assim, tem-se que o referencial de Nancy Fraser se faz determinante, no sentido de considerarmos que o reconhecimento é uma questão de justiça e, por meio deste podemos atingir o ideal de paridade de participação, em um primeiro momento. A perspectiva de Fraser é a mais apropriada para trabalhar a temática referente à 
concretização dos direitos das minorias gays e lésbicas no âmbito do Supremo Tribunal Federal, pois estes são grupos (minorias) excluídos do processo político e que, aos poucos, vão conquistando reconhecimento - legal e social - e, atingindo a paridade de participação proposta pela socióloga.

À luz de Fraser (2003a; 2010), arremata-se que, embora Honneth (2003a; 2012; 2015) teorize um relevante diagnóstico de opressão contra minorias, sua perspectiva é insuscetível de se contrapor ao binarismo sexual. De fato, o voto do Ministro-Relator, ao resgatar os princípios da liberdade e da intimidade, enfatiza que "[...] tudo aquilo que não estiver juridicamente proibido, ou obrigado, está juridicamente permitido", com base no art. 5º II da Constituição Federal de 1988, consagrando implicitamente a ideia de liberdade social, tal como delineada por Honneth (2015).

Entende-se que somente a criação de novos contrapúblicos subalternos que ampliem novas interpretações de necessidades não ouvidas na esfera pública oficial torne viável o combate à inexpressividade ou à ausência de voz. Nesse particular, o modelo de status proposto por Fraser (2003a; 2003b; 2010) é deontológico, não apelando para a concepção de autorrealização ou de bem, mas para a concepção de justiça democraticamente estabelecida, que pode ser aceita e justificada por indivíduos com concepções divergentes de bem.

Nessa perspectiva, Fraser $(1992 ; 2001 ; 2003 a ; 2003 b ; 2010)$ explana recursos conceituais que revelam maior alcance teórico para interpretar e para criticar o voto do Ministro-Relator e dos Ministros Gilmar Mendes e Ricardo Lewandowski, propugnando uma teoria feminista que se contrapõe à essencialização identitária e ao binarismo de gênero - mas sem anular a autonomia do sujeito - assumindo como objetivos a descrição das desigualdades e a formulação de um projeto emancipatório, por meio de contrapúblicos subalternos. Então, enquanto Honneth (2003a; 2012; 2015) compreende o reconhecimento como forma de autorrealização, Fraser (2003a; 2003b; 2010) parte da perspectiva de que se trata de uma questão de justiça social que reflete a dimensão tridimensional voltada para atingir a paridade de participação entre todos os membros da sociedade.

\title{
THE JUDGMENT OF THE ADI 4.277: ANALYSIS OF THE VOTES OF THE STF MINISTERS IN THE LIGHT OF THE THEORY OF RECOGNITION OF NANCY FRASER AND AXEL HONNETH
}

\begin{abstract}
The general objective is to study the debate between Fraser's and Honneth's theoretical foundation, with its reflexes in the judgment of ADI 4277-DF by the STF, criticizing implicit discourses insusceptible to destabilize the binary sexual identities. As specific objectives it is tried to critically confront the theoretical references of the mentioned philosophers; reveal and criticize the argumentative strategy presupposed to the votes of the STF
\end{abstract}


Justices in the judgment of ADI 4277-DF, to understand which of the philosophical theories has a greater theoretical scope to interpret and criticize the votes. By way of final considerations, it is possible to understand that Fraser explores conceptual features that reveal a greater theoretical scope for interpreting and criticizing the vote of the presiding Justice and Justices Gilmar Mendes and Ricardo Lewandowski, advocating a feminist theory that opposes the essentialization of identity and binarism of gender - but without canceling the autonomy of the subject - assuming as objectives the description of inequalities and the formulation of an emancipatory project, through subaltern counterpublics. For this, the research is structured by the phenomenological-hermeneutic method. The analytical induction method (approach method) will also be used. The research technique will involve indirect documentation and documentary research will be used.

Keywords: Sexual Binarism. Fundamental rights. Minorities. Theory of Recognition. Marriage between same-sex couples.

\section{REFERENCIAS}

BRASIL, Supremo Tribunal Federal. Acórdão em que deu provimento ao pedido de interpretação conforme a Constituição ao artigo 1723 do Código Civil. Arguição de Descumprimento de Preceito Fundamental n. 132. Procuradoria Geral da República. Voto do Ministro Relator, Carlos Ayres de Brito. Data de julgamento: 4 e 5 de Maio de 2011a. Disponível em: <http://redir.stf.jus.br/paginadorpub/paginador.jsp?docTP=AC\&docID=628633 >. Acesso em 6 de novembro de 2015.

Supremo Tribunal Federal. Acórdão em que deu provimento ao pedido de interpretação conforme a Constituição ao artigo 1723 do Código Civil. Arguição de Descumprimento de Preceito Fundamental n. 132. Procuradoria Geral da República. Voto do Ministro Gilmar Mendes. Relator: Ministro Carlos Ayres de Brito. Data de julgamento: 4 e 5 de Maio de 2011b. Disponível em: < http://redir.stf.jus.br/paginadorpub/paginador.jsp?docTP=AC\&docID=628633 >. Acesso em 6 de novembro de 2015.

Supremo Tribunal Federal. Acórdão em que deu provimento ao pedido de interpretação conforme a Constituição ao artigo 1723 do Código Civil. Arguição de Descumprimento de Preceito Fundamental n. 132. Procuradoria Geral da República. Voto do Ministro Luiz Fux. Ministro Relator: Carlos Ayres de Brito. Data de 
julgamento: 4 e 5 de Maio de 2011c. Disponível em: < http://redir.stf.jus.br/paginadorpub/paginador.jsp?docTP=AC\&docID=628633 >. Acesso em 6 de novembro de 2015.

Supremo Tribunal Federal. Acórdão em que deu provimento ao pedido de interpretação conforme a Constituição ao artigo 1723 do Código Civil. Arguição de Descumprimento de Preceito Fundamental n. 132. Procuradoria Geral da República. Voto da Ministra Carmem Lúcia. Ministro Relator: Ministro Carlos Ayres de Brito. Data de julgamento: 4 e 5 de Maio de 2011d. Disponível em: http://redir.stf.jus.br/paginadorpub/paginador.jsp?docTP=AC\&docID=628633.>Acesso em 6 de novembro de 2015.

Supremo Tribunal Federal. Acórdão em que deu provimento ao pedido de interpretação conforme a Constituição ao artigo 1723 do Código Civil. Arguição de Descumprimento de Preceito Fundamental n. 132. Procuradoria Geral da República. Voto do Ministro Joaquim Barbosa. Ministro Relator: Ministro Carlos Ayres de Brito. Data de julgamento: 4 e 5 de Maio de 201 le. Disponível em: < http://redir.stf.jus.br/paginadorpub/paginador.jsp?docTP=AC\&docID=628633>. Acesso em 6 de novembro de 2015 .

Supremo Tribunal Federal. Acórdão em que deu provimento ao pedido de interpretação conforme a Constituição ao artigo 1723 do Código Civil. Arguição de Descumprimento de Preceito Fundamental n. 132. Procuradoria Geral da República. Voto do Ministro da Ministra Ellen Gracie: Ministro Relator: Carlos Ayres de Brito. Data de julgamento: 4 e 5 de Maio de 2011f. Disponível em: <http://www.stf.jus.br/portal/cms/verNoticiaDetalhe.asp?idConteudo=178937>. Acesso em 6 de novembro de 2015.

Supremo Tribunal Federal. Acórdão em que deu provimento ao pedido de interpretação conforme a Constituição ao artigo 1723 do Código Civil. Arguição de Descumprimento de Preceito Fundamental n. 132. Procuradoria Geral da República. Voto do Ministro Celso Mello. Relator: Ministro Carlos Ayres de Brito. Data de julgamento: 4 e 5 de Maio de 2011g. Disponível em: <http://redir.stf.jus.br/paginadorpub/paginador.jsp?docTP=AC\&docID=628633>. Acesso em 6 de novembro de 2015.

Supremo Tribunal Federal. Acórdão em que deu provimento ao pedido de interpretação conforme a Constituição ao artigo 1723 do Código Civil. Arguição de Descumprimento de Preceito Fundamental n. 132. Procuradoria Geral da República. Voto do Ministro Marco Aurélio. Relator: Ministro Carlos Ayres de Brito. Data de julgamento: 4 e 5 de Maio de 2011h. Disponível em: <http:// http://redir.stf.jus.br/paginadorpub/paginador.jsp?docTP=AC\&docID=628633 >. Acesso em 6 de novembro 
de 2015 .

Constituição Federal. Brasília: Senado Federal, 1988. Disponível em: <http://www.planalto.gov.br/ccivil_03/Constituicao/Constituicao.htm >. Acesso em 1 de Maio de 2015.

Resolução n. 175, de 14 de Maio de 2013. Dispõe sobre a habilitação, celebração de casamento civil, ou de conversão de união estável em casamento, entre pessoas do mesmo sexo. Brasília: Conselho Nacional de Justiça, 2013.2 Disponível em: <http://www.cnj.jus.br/images/imprensa/resolu\%C3\%A7\%C3\%A3o_n_175.pdf>. Acesso em 1 de Maio de 2015.

BUNCHAFT, Maria Eugênia. Ativismo judicial grupos estigmatizados: Filosofia Constitucional do Reconhecimento. Curitiba: Juruá, 2014.

FRASER, Nancy. Da redistribuição ao reconhecimento? Dilemas da justiça na era pós-socialista. In: SOUZA, Jessé (org). Democracia Hoje. Novos desafios para a teoria democrática contemporânea. Brasília: Editora UNB, 2001.

Distorted Beyound all Recognition: A Rejoinder to Axel Honneth. In: FRASER, Nancy; HONNETH, Axel. Redistribution or Recognition?-A Political Philosophical Exchange. London: Verso, $2003 \mathrm{~b}$.

Justice Social in the Age of Identity Politics. In: FRASER, Nancy; HONNETH, Axel. Redistribution or Recognition?-A Political Philosophical Exchange. London: Verso, 2003a.

Prioritizing Justice as Participatory Parity. A reply to Kompridis and Forst. In: OLSON, Kevin (ed.). Adding Insult to Injury: Nancy Fraser debates her critics. London: Verso, 2008.

Reconhecimento sem ética? In: SOUZA, Jessé; MATTOS, Patrícia. Teoria Crítica no Século XXI. São Paulo: Annablume, 2007.

Recognition without Ethics? Theory, Culture \& Society, vol 18, n. 2-3. London: Sage Publications, 2001.

Rethinking the Public Sphere: a Contribution to the Critique of Actually Existing Democracy. In: CALHOUN, Craig. Habermas and the Public Sphere. Cambridge: Mit Press, 1992.

Scales of Justice: Reimagining political space in a globalizing world. New York: Columbia University Press, 2010 .

HONNETH, Axel. Democracia como Cooperação Reflexiva. John Dewey e a Teoria Democrática hoje. In: SOUZA, Jessé (org.). Democracia hoje - Novos desafios para a teoria democrática contemporânea. Brasília: UNB, 2001. 
Invisibility: on the epistemology of recognition. In: Supplement to the Proceedings of the Aristotelian Society, volume 75, n. 1, 2001.

Luta por reconhecimento. A gramática moral dos conflitos sociais.São Paulo: Ed. 34, 2003 a.

O direito da liberdade. São Paulo: Martins Fontes, 2015.

Recognition or Redistribution? Changing Perspectives on the Moral Order of Society. Theory, Culture \& Society, vol 18, n. 2-3. London: Sage Publications, 2001.

Redistribution as Recognition: a Response to Nancy Fraser. In: FRASER, Nancy; Redistribution or Recognition. Londres/New York: Verso, 2003b.

The Point of Recognition: A rejoinder to the rejoinder. In: FRASER, Nancy; HONNETH, Axel. Redistribution or Recognition. Londres/New York: Verso, 2003c.

LARA, Maria Pia; FINE, Robert. In: LOVELL, Terry (Ed.). (Mis) recognition, Social Inequality and Social Justice: Nancy Fraser and Pierre Bourdieu. London and New York: Routledge, 2007.

LOPES, José Reinaldo de Lima. Comentando a decisão do STF. In: RIOS, Roger Raupp (Org.); LEIVAS, P. (Org.); GOLIN, C. (Org.). Homossexualidade e direitos sexuais: reflexões a partir da decisão do STF. 1. ed. Porto Alegre: Editora Sulina, 2011.

SOBOTTKA. Emil A. Liberdade, Reconhecimento e Emancipação - raízes da teoria da justiça de Axel Honneth. Sociologias, Porto Alegre, ano 15, n 33, mai./ago. 2013, p. 142-168

Trabalho enviado em 20 de junho de 2018

Aceito em 17 de setembro de 2018 